\title{
Can Story-Making and Role-Playing Pedagogy Arise Young Students' Interest and Efficiency of Vocabulary Learning in English Class?
}

\author{
Yuxin $\mathrm{Liu}^{1, \dagger}$, Yingli $\mathrm{Na}^{2, \dagger}, \mathrm{Lu} \mathrm{Yu}^{3, *, \dagger}$ \\ ${ }^{1}$ School of liberal arts and science, University of Washington, Washington, 98195, USA \\ ${ }^{2}$ Faculty of Health and Life Sciences, Coventry University, Coventry, England, CV1 5FB, UK \\ ${ }^{3}$ School of Foreign Languages, Cangzhou Normal University, Cangzhou, Hebei, 061000, China \\ ${ }^{*}$ Corresponding author. Email: yuxinl.19@uw.edu
}

These authors contributed equally.

\begin{abstract}
With the continuous development of education, various teaching methods have been applied to the class. In the recent decade, game class, especially in preschool education, has been paid more and more attention. The application of game teaching methods such as story-making and role-playing in the English education of young students is more conducive to stimulating their interest in learning and promoting the continuous development of their English learning ability. Accordingly, we carried out a control experiment to observe whether adding games in class could effectively improve students' interest in learning. Three children, aged 3-7, were taught four English words by different group members and told stories to consolidate their memories. After the experiment, video and CA transcription were used to analyze the teaching process. The problems encountered in the experiments were mainly analyzed from the following three perspectives - teacher, student, and class. Then, pilot data were derived. The study results show that the scope of the pilot data could not include all English learners due to the age limitation of the participants. At the same time, because of the time limitation and the number of experiments, the pilot data is not enough to prove the effectiveness of the game class. Finally, the direction and steps of further specific experiments are proposed in this research.
\end{abstract}

Keywords: Store-making, Role-playing, Young students, English vocabulary learning.

\section{INTRODUCTION}

Young students are more likely to be distracted than adults. Hence, teachers should choose suitable teaching methods for young students. This paper explores whether story-making and role-playing pedagogy can raise young students' interest and efficiency in vocabulary learning in English class. The game teaching method can greatly improve their attention to class. Teachers can achieve better teaching effects by using game teaching methods such as story-making and role-playing, especially in the vocabulary class. This paper is divided into five parts. The first part deals with a literature review of the interaction in the classroom and the game class, including story-making and role-playing. The second part describes the method of the experiments. The third part discusses the result of the experiments. The fourth part analyses the pilot data of the experiments. The fifth part proposes the suggestions for the experiments and the steps of further specific experiments.

\section{LITERATURE REVIEW}

This section presents and discusses theoretical and empirical literature about the influential elements in the classroom and pedagogies, which deliver an attractive class to increase students' learning interests and performances.

\subsection{Interaction in the Classroom}

Learning is not a single-thread program that involves knowledge, students, or teachers only. According to social constructivism, learning cannot be separated from social interaction and collaboration [1]. In Vygotsky's theory- Zone of Proximal Development, the learning 
happens where the learner needs guidance or interaction of others to solve problems and understand the knowledge [1]. Therefore, in a classroom context, the interaction between teachers and the students and between students and peers is significant.

An efficient interaction can also promote students' motivation on learning, and motivation is one of the essential factors that would determine the second language learners' achievements [2]. Dobbs and her colleagues found that the amount and types of preschool teachers' attention received by students would directly impact students' classroom behaviour and school experience [3]. To be more specific, the students would change their behaviours according to the teacher's reactions and their predictions to teachers' rewards or punishments.

Generally, the information transmission can be arranged into two types: one is the code and inference model of communication that using language to explain it, another one is the simulation model of communication, which can be referred to the method of employing images, voices, and activities to deliver the message [4]. To deliver the knowledge and demand precisely, the teacher can produce an effective interaction.

There are advantages for both types of information transmission. Still, it is difficult for young language learners to apply code and inference models of communication because children do not have access to meta-language, which means it is hard for them to learn language by using language (including learning a same or different language) [5]. Therefore, it is necessary to use the simulation communication model in a language class for young students.

Language classes for young learners usually involve using images, video, audio, narratives, computers, media, and activities with or without props. Studies probe into these different methods reveals that they all possessed some levels of advantages respectively or conjointly [68]. Furthermore, these teaching methods can be arranged by the extent of interaction between teacher and students: The one using materials (e.g., images) refers to a lower extent of interaction (the control group in this research), whereas another one using activities refers to a greater extent of interaction (the experimental group). Therefore, this research investigates the different performances in language classes between two levels of teacher-student interaction.

\subsection{Storytelling Class}

Storytelling is a valuable pedagogy for language learning due to its accessible and deliverable features. According to Bruner, stories present the experience of human or human-like characters, where the author can implant information, thus assisting the students in comprehending, even those intricate concepts and knowledge [9]. Castro presents that "Storytelling is an authentic resource to be introduced because it allows students to participate actively in the learning process" [10]. For example, in Archer's research, the teacher read a story about a strange indeterminate character who is shapeless and absent. The 6-year-old students can understand that its features are unable to estimate [11].

This teaching method normally imports stories into classes in different ways that include: teacher reads stories to students; students read the stories; students create stories independently or under teacher's guidance $[11,12]$. Researches suggested that despite the ways how stories implant in the classes, it improves the quality of the class by increasing students' interest and understanding. In González's study, the teacher created the stories used in a second language class, but the characters were selected by the students [12]. Injecting those stories in the class significantly promoted students' learning motivation and comprehension of the vocabulary in the stories.

\subsection{Role-playing Class}

Role-playing class is another teaching strategy suggested as student and activity centred, which involves the high cognitive level of teacher-students and studentsstudents interaction. It stimulates student engagement, also provides the teacher with an efficient way to gain knowledge of each student and their degree of achievement. Research comparing role-playing classes with traditional teaching styles revealed that students who participated in the former perform better than the latter [13]. Furthermore, role-playing can be applied in an online university class, assisting the students in producing deep understandings and reflections on the knowledge, and leading to sustained interest in their subject [14].

Role-playing class possessed the same benefit to children's language learning, specifically on the 'listening', 'speaking' and 'vocabulary.' This strategy provides children with an opportunity to practice their language skills under different communicative conditions [15]. However, the role-playing class for young children is usually pre-scripted rather than improvisational due to their cognitive development level [15]. It requires the teacher to prepare for the class and to choose the teaching materials carefully.

\section{METHODS}

\subsection{The Introduction of the Experiment}

This research will be qualitative research that takes three one-by-one English classes as examples to investigate whether story-making and role-playing game classes would arise students' interests and learning performances. 


\subsection{Participants}

Young learners in this research would be assigned into two groups. One is a control group that would learn new vocabularies by regular class. The teacher would use pictures and props to deliver the new words; another is an experimental group that students would be involved in story-making and role-playing game-class.

Participants were aged from 3 years old to 7 years old. The control group is a kindergarten English class video that was found on the internet. The experimental group is three young learners who have been learning English as a second language for several years: a 6 years old boy, a 6 years old girl, and a 7 years old boy.

\subsection{Teaching Materials}

The vocabularies used in the class were selected from different vocabulary pools according to students' English levels. It is the Chinese standard English book for grade 1 volume 1, the Chinese standard English book for grade 2 volume 1, and the Wonders reading for grade 3 unit 5 for each child, respectively.

The new words taught in the one-by-one game class were:

1) 'teacher', 'schoolbag', 'ruler', and 'pencil' for the 6 years old boy;

2) 'Christmas', 'lake', 'zoo', and 'friend' for the 6 years old girl;

3) 'accidental', 'disasters', 'careless' and 'prevention' for the 7 years old boy;

\subsection{Teaching Procedures}

In the experimental group, the class for the 6 years old girl was a face-to-face class, two online classes for the other two boys due to the limitation of the environment. After that, the teaching procedure was the same.

The instructor and student introduced themselves at first, and then the instructor started her class by introducing the new word and explaining its meaning one by one to the student. After that, the instructor asked the student to make one sentence with one new word respectively until completing all four new words. Then the instructor asked the student to connect all these four sentences as a short story. At the end of the class, the instructor tested the student to examine vocabulary learning efficiency.

To increase students' engagement, the sentences and stories were all involved in students' personal real life (e.g., describing his daily school activities) or ideal life, which referred to his dream future job.

\subsection{Data Analysis Approach}

The three experimental one-by-one classes were video recorded. The control group video was found from the internet. The transcript for both would be analysed by Conversation Analysis (CA) approach.

\section{RESULTS}

Rossiter stated that stories are more authentic and credible which information they contained is easier to remember [16]. However, the results of the experiment deviated from expectations due to the influence of many factors such as time limitation, teaching method. The advantage of story-making game class in vocabulary class is not obvious. It cannot be proved that game class can effectively improve students' interest and efficiency in learning. Through the analysis of the class videos, we found that the problems mainly focus on three aspects: teachers, students, and class. This chapter will analyze the above three aspects in detail.

\subsection{Perspective of Teacher}

Influenced by the age and cognition of the participants, the experiment is still teacher-led teaching. Hence, the teacher's behavior and subjective consciousness will greatly affect the results of the experiment.

Firstly, it is difficult for teachers to assess students' current learning levels because they are not familiar with each other. From experiment 2, when teaching students new words, the teacher did not even know whether the students understood the Chinese meaning of the new words, making our class more difficult to carry out. Vygotsky pointed out the concept of the zone of proximal development, which is the distance between the actual developmental level and the potential developmental level [1]. If teachers can fully understand students' cognitive level before teaching, they can better use students' zone of proximal development to select suitable words for students to learn.

Secondly, the teacher's teaching proficiency and the degree of sensitivity to knowledge also affect the class. Immature teachers will subconsciously ignore the inherent logic between the knowledge itself, making it difficult for students to connect the new words to form a complete story.

\subsection{Perspective of Students}

As the core of the class, students' characteristics have a particularly important impact on the progress of the game class. Firstly, we found that some students did not understand the specific concepts used by teachers in the class, including "story-making", which may result from immature development level and personal experience. In 
experiment 1 , for example, the student was confused by the teacher's request to "tell a story and use the four words learned". Then after the teacher explaining to the demand, the student still thinking until the teacher gave the student an example. He finally told a story by himself, which is similar to the teachers. In experiment 2, the student did not understand the meaning of the word "prevention," and the teacher spent too much time explaining in different ways to make sure the student remembered the meaning of "prevention" but did not understand it. However, the student forgot to use the word "prevention" in the latter part of the story-making.

Secondly, gender also affects language learning. Some studies have pointed that women develop language learning and empathy earlier than men. The student in experiment 3, the only female, was superior to the students in the other two experiments in terms of concept understanding, teacher-student interaction, and word use.

\subsection{Perspective of Class}

The class is the bridge that links teacher and student. The teaching content and atmosphere of the class will also have a great impact on teaching quality. First of all, parents' excessive guidance made students become dependent and lose the ability to autonomous thinking. At the same time, it disrupted teachers' thinking. In experiment 1, the participant's mother was present throughout the experiment and provided guidance from time to time. According to the video, the participant would turn to his mother for help when he could not express himself in English, even though much of the interaction was between the mother and the child. This also affects the teacher's teaching process.

Secondly, the class lacks the necessary interaction between students. The communication and discussion between students can form a benign atmosphere and make students fully integrate into the class. However, each of the three experiments had a single participant, and the interaction in the class was only between teachers and students. At the same time, due to the differences in cognition and roles between teachers and students, students may be nervous, which will hinder the stimulation of their imagination, and the effect of the interaction is not good either.

Finally, due to improper vocabulary and stories, students have no interest in learning, which greatly affects the game class's development. In experiment 2, at first, the student was told to narrate a story by using the word firefighter, but the student was not familiar with this career, which led to the student refuse to tell a story. The teacher then connected the story to the student's dream career, which pushed him to have a passion for interacting with the teacher and completing the story. The change of students' attitudes also reflects that students' sensitivity to the teaching content determines whether the game class can carry out successfully to a certain extent.

\section{DISCUSSION}

\subsection{Preconditions}

To follow up with the experiment, the experiment group results should be compared with the control group to analyze and discuss the difference, successes, and faults. As the result showed, a bunch of problems showed up from the experiment, but also advantages.

To start, some issues should be cleared, and there are some differences in the precondition between the control group and the experiment group. Firstly, in the control group, the students are first language learning, but in the experiment group, all the three students are second language learners. Secondly, the format of the control group is in the physical classroom instead of the experiment group is mostly online classes.

Come back to the final purpose of the experiment, and the aim is to examine whether the change of classroom teaching method will trigger students' interest and study efficiency. Using the game teaching method to teach English vocabulary enables young students to use the language more creatively while keeping their interest in learning [17]. The storytelling class can provide the students with a meaningful learning environment, and the efficiency of the L2 classroom will be ensured [12]. The experiment is to show how well the students remember the new words. Due to the time limitation of the experiment, teachers could not be fully prepared. For example, the class time should be longer so that the teacher can add more games in the class, such as tongue twister, role play. Teachers will also have better control over the class, which includes providing the body language and some verbal instructions for role play if they can teach students face to face. The teachers can better understand the students by receiving the sounder knowledge; also, the students will be very beneficial by interacting with materials and peers [14]. Both experiment 1 and experiment 2 adopted online teaching, which was far less effective than the face-to-face teaching of experiment 3 . In addition, teaching aids such as masks for role play, word cards and the real things of the learned words were not prepared for students. The object teaching method can greatly stimulate students' interest in learning, especially for young students. If teachers use teaching aids in class, the interaction between teachers and students will be better. In short, the time limitation had a great influence on our experimental results.

\subsection{Perspective of Teacher}

To start comparing the two groups, the first aspect is from the teacher's angle, as the result stated that the 
teachers are lack knowledge about the students' current level, which is not a problem in the control group. After analyzing the video, it shows the professor can highly flexibly use the teaching method when facing different situations. In the students' learning process, the teacher needs to provide enough guidance, including helping the students simulate and afterwards reflect [18]. By looking at the clip, the teacher can lead the students step by step and gradually forward the process. For example, when the students do the game to find the missing word, they can successfully find the missing word although they still need some guidance from the teacher.

\section{Transcript 1}

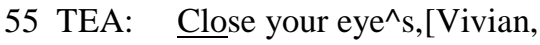

56

\section{$[(($ Turns to \\ a student))}

57 STU: ((Vivian covers her eyes $)$ )

58 TEA: Yes,[goo:d.(2.0) What's missing

$[(($ Takes away a card $))$

60

[Open your eye ${ }^{\wedge} \mathrm{s}$. What's $\mathrm{mi}^{\wedge} \mathrm{ssing}$.

\section{STU: [((Put their hands down $))$}

\section{Doll}

62 TEA: Doll.==[Very goo:: $\mathrm{d}$.

Another problem found is that the word provided for the students lacks logic, which is also a problem in the video. The words that the professor provides to the students are easier, but the students need to learn each word individually instead of connecting together. Although in the experiment, the words are not at the appropriate level of the students' knowledge but still can provide enough logic to let the students make a story.

\subsection{Perspective of Students}

Secondly, these two groups can be compared from the student aspect. The first result analyzed from the student aspect is that the development level and personal experience make them unable to have the level of knowledge to fully understand the new words. Although in the control group, there was no information about the students' background, by looking at the video and the CA transcript of the video, it shows that the students will lose their interest sometimes and do their own things. Also, the process of the class is not forwarding fluently. For example, if the teacher stops guidance in the video, the students cannot repeat the words by themselves very well.

\section{Transcript 2}

19 TEA: [Plane:?
[Doll.

$[(($ Points to the doll card $))$

23 STU: [((Left one child plays the chair $))$

24

[((Middle one looks at the card $))$

25

$[(($ Right one looks at the teacher $))$

\section{TEA: [((Claps one time $))$}

27

$$
\left[\operatorname{Tedd}^{\wedge} \mathrm{y}\right]
$$

It can be further indicated that the class material did not fit their development level. They are not even fully repeat the words. From this aspect, it can show the advantage of the experiment group that the students' development level has adjusted the words given to the students. The second interpretation is the gender difference, which cannot show from the control group very well, mostly. In the video, the teacher interacted with the students as a whole group rather than teaching with individuals like the experiment group. Hence, there should be further analysis of the motion and microexpressions of the students to interpret the difference of the gender aspect.

\subsection{Perspective of Class}

Finally, from the class perspective analysis, in the experiment group, it can show the parent's over guidance, which the control group did a better job. In the control group, the only guidance is the teacher himself, which is an advantage and a disadvantage. As an advantage, there will not be another adult to give different guidance, confusing the students. As a disadvantage in the control group, the teacher only has one person as himself. When the students cannot focus their attention, it is hard for the teacher to bring all of their focus back. For example, the teacher tries to attract the students by clapping his hands in the video, but it does not work very well.

\section{Transcript 3}

27 TEA: [Tedd $\left.{ }^{\wedge} \mathrm{y}\right]$

28 ((Points to the teddy card $)$ )

((Claps three times))

30 STU: ((Clap listless $))$

((Clap several times $))$

31 TEA: $\left[\mathrm{Pla}^{\wedge} \mathrm{ne}\right](2.0) \mathrm{do}^{\wedge} \mathrm{ll}$

32 STU: $\quad[(($ Continue clapping $))$

33 TEA: $\quad\left[\mathrm{Ca}^{\wedge} \mathrm{r}\right.$

34 STU: $\quad[(($ A girl looks away (2.0) $))$

However, in the experiment group, the parents can easily attract the students' attention back. Another point is that there is a lack of peer interaction in the experiment group, which is also a problem found in the control 
group. Although there are multiple students in the classroom, they do not interact with each other. There should have further experiments to see does effective peer interaction can make students have more interest and higher efficiency.

\section{CONCLUSION}

In the research project, we found two groups to compare whether story-making and role-playing style classes will trigger the interest and efficiency of students. After completing the experiment that compares a regular class with the game class, there are a couple of problems as the results showed, the problems are shown from teachers, students, and class three aspects. After the result and discussion, there are a couple of suggestions that our research group has for the problems for any possible further experiments. There should be further understanding of the students' development level; the experiment process should also be more well prepared. To follow the cognitive law, there should be experiments more fit for the students. The distractions found from the research from different aspects should be eliminated too. Another point that worth mention is that the feedback of the students is positive. One girl keeps repeating the words after the class, which is a good outcome that features, she learned the words. There is also the scope of the result. Due to the target participants are 3-7 years old children, our theory may not fit for other age groups. If there will be a further experiment, the age group can be enlarged.

\section{REFERENCES}

[1] Vygotsky, L. (1978). Interaction between learning and development. In Mind and Society (pp. 79-91). Cambridge Ma: Harvard University Press.

[2] Dörnyei, Z. (1994). Motivation and Motivating in the Foreign Language Classroom. The Modern Language Journal., 78/3, 273-284.

[3] Dobbs, J., Arnold *, D. H., \& Doctoroff, G. L. (2004). Attention in the preschool classroom: the relationships among child gender, child misbehavior, and types of teacher attention. Early Child Development and Care, 174(3), 281-295. doi:10.1080/0300443032000153598

[4] Bergman, M., Kirtiklis, K. s., \& Siebers, J. I. (2020). Models of communication: theoretical and philosophical approaches. New York, NY: Routledge.

[5] Cameron, L. (2001). Children learning a foreign language. In Teaching Languages to Young Learners (pp. 1-20).

[6] Chen, J., Wang, M., Kirschner, P. A., \& Tsai, C.-C. (2018). The Role of Collaboration, Computer Use,
Learning Environments, and Supporting Strategies in CSCL: A Meta-Analysis. Review of Educational Research, 88(6), 799-843. doi:10.3102/0034654318791584

[7] Disusun Oleh, A. M., Moh. Ikbal Harun, Rosmin Mohamad Ani. (2015). Teaching English for Young Learners. English For Specific Purposes (ESP). English Education Department Faculty Tarbiyah And Teachership. Dipresentasikan Pada Mata Kuliah English For Specific Purposes Dosen Pengampuh Abdul Kadir Ismail S.Pd., M.Hum.

[8] Ya, L. (2020). An Analysis of the Application of Game Teaching Method in Oral English Class of Preschool Education. Educational Research, 3(9), 102-104. doi:10.25236/FER.2020.030925

[9] Bruner, J. S. (1986). Actual minds, possible worlds. Cambridge, MA: Harvard University Press.

[10] Castro, M. (2002). The Magic World of Storytelling: Some Points for Reflection. Profile Issues in Teachers' Professional Development, 3(1), $52-54$.

[11] Archer, T. (2003). Conceptualization Of The Unknown By 6-, 9- And 14-Year-Old Children In A Story-Telling Context In search of a 'heffalump'. Childhood, 10(3), 379-392. doi:0907-5682 (200308) 10:3; 379-392;034584

[12] González, N. I. P. (2010). Teaching English through Stories- A Meaningful and Fun Way for Children to Learn the Language. Bogotá Colombia, 12(1), 95106.

[13] J. P. McCarthy, L. Anderson. (1997). Active learning techniques versus traditional teaching styles: Two experiments from history and political science. Innovative Higher Education, 24(24), 279294.

[14] Bender, T. (2005). Role playing in online education: A teaching tool to enhance student engagement and sustained learning. Innovate, 1(4).

[15] S. Shapiro, L. Leopold. (2012). A Critical Role for Role-Playing Pedagogy. TESL CANADA JOURNAL, 29(2).

[16] Rossiter, M. (2002). Narrative and stories in adult teaching and learning. Retrieved from Washington, DC:

[17] Bakhsh, S. A. (2016). Using Games as a Tool in Teaching Vocabulary to Young Learners. English Language Teaching, 9(7), 120-128.

[18] Erturk, E. (2015). Role Play as a Teaching Strategy. Paper presented at the National Tertiary Learning and Teaching Conference. 